\title{
Mobile Computing as a Support to Teach the Concept of Function
}

\author{
Elena Fabiola Ruiz Ledesma \\ Sección de Estudios de Posgrado e Investigación. \\ Escuela Superior de Cómputo-IPN \\ Distrito Federal, México \\ efruiz@ipn.mx
}

\author{
Juan Jesús Gutiérrez García \\ Sección de Estudios de Posgrado e Investigación \\ Escuela Superior de Cómputo-IPN \\ Distrito Federal, México \\ jjggarc@gmail.com
}

\begin{abstract}
We make a proposal to teach the concept of function using mobile computing. This proposal is based on research that has support in education theories such as Constructivism and Problem Solving Learning. In the first part we show the difficulties that undergraduate Computer Science students have in the first semester of Engineering while working with that mathematical concept. And application to be used by the students anywhere and anytime in mobile devices is designed that process data and is intended to show them the concept of function in a problem solving situation. The proposed activities are part of the education methodology used in the research and within this paper we show the diagnostic questionnaire as one of the methodological tools and its results supporting the designed activities and its application to mobile devices.
\end{abstract}

Keywords-mobile computing; technology; constructivism; function.

\section{INTRODUCCIÓN}

Mobile devices have made great progress in recent years and are influencing all activities. For this reason groups like New Media Consortium, EDUCAUSE and Learning Initiative point out through their projects Horizon Report [1]-[3], the use of mobile devices in education as one of the developing research lines in recent years.

Additionally, there is "educational" software on the market, especially built for mobile devices and developed for different purposes: fun, acquiring proficiency in a subject, present information about a course, solving puzzles, etc. These materials are disorganized and there is not a study. about their

\section{A. Problem Statement}

In the absence of contextualized mobile computing applications that support teaching and learning processes, we take advantage and measure usability provided by M-Learning to develop a teaching proposal for the topic of function, as a case of study.

It is also considered that the Mobile Computing could support and enhance the teaching-learning process, as current students have a mobile culture Kurlovskey [4], which implies that they have prior knowledge that should be exploited as mentioned Ausubel [5]. influence in the Teaching-Learning Process (TLP). Disciplines like Mathematics Education allow researchers to investigate how to get inside a classroom with these devices linking technology and theoretical work on learning.

One goal of this work is to take advantage of both disciplines, Mobile Computing and Mathematics Education, in order to teach calculus, focusing on the concept of function.

In different researches regarding the difficulties students have in learning mathematics, authors note that one issue is due to the way how the content is structured in the classroom, preferentially oriented to the purely mathematical aspect, based on exercise and algorithms management without a link to real-world and science problems. This leads to a lack of interest of students in the study of mathematics because they don't conceive its use in their studying process as mentioned by Aravena [6\}, [7], and Biembengut [8].

Artigue [9] states:

"... According to the difficulties found, the traditional teaching and in particular, university education, even if they have other ambitions, tends to focus on algorithmic and algebraic practice of calculus and evaluate the acquired skills in that domain. This phenomenon becomes a vicious cycle. To have acceptable levels of success, it is assessed what students can do better, and this is, in turn, is considered as essential by students because that is what is assessed ... "

"If I had to reduce all of educational psychology to just one principle I would say that: the most important factor influencing learning is what the learner already knows. Ascertain this and teach accordingly"

\section{B. Theoretical Aspects}

In this section we point out the concepts involved in the construction of the tools used in this research.

At first Mobile Computing is described and its relation towards education, which gives rise to M-Learning. Later education methodologies employed and finally some learning problems that were addressed in the research. 


\section{1) Definition of Mobile Computing}

There are several definitions for Mobile Computing systems, in this paper we take the approach outlined by B'Far [10]:

"Mobile Computing Systems are Informatics Systems that can be moved easily in a physical way and whose computing capabilities can be used while moving" (p. 3).

According to this definition mobile informatics systems distinguishes themselves from other computer systems, taking into account the differences between the tasks they are designed to perform, how they are constructed, and how they are used. This identifies four characteristics of mobile devices: mobile user, mobile device, mobile application and mobile network.

A mobile user is defined under the following conditions of mobility:

- Being on the move, at least occasionally, alternating between known and unknown locations.

- The user's attention is not focused primarily on the computational task performed. When in motion requires attending other activities.

- Require short times of response from a system with a high degree of interactivity.

- Change frequently or abruptly between tasks.

- Require digital access to information anytime, anywhere

On the other hand we have the characteristics of a Mobile Computing System, which is known as mobility dimension by B'Far [10]:

- Location awareness,

- Network connectivity quality of service (QOS),

- Limited device capabilities (particularly storage and CPU),

- Limited power supply,

- Support for a wide variety of user interfaces,

- Platform proliferation, and

- Active transactions.

The location can be seen on two levels: to obtain information about the location of the device and how this information is used in the system functionality.

On the other hand the information technologies based on Internet, has been involved in all human activities including education, giving rise to what is known as ELearning. This is defined as the use of Internet technologies to provide a wide range of solutions that improve the process of obtaining knowledge by Chuanto [11]. The development of E-Learning techniques has given rise to other related activities such as T-Learning, U-Learning, M-Learning, (television, ubiquitous and mobile, respectively). The latter is described as the intersection of distance learning using the Internet (ELearning) and Mobile Computing.

M-Learning is divided into two categories: first, the actor is independent of his context and location, only makes use of the mobile device for learning, such as listening to music in English to learn the language; in the second, the actor is placed in a context that is necessary to carry out the learning process. This second category is known as context-aware mobile learning Chuanto [11].

The context required for the M-Learning is, in the information used to characterize the learning situation in order to be relevant to the interaction between student and mobile application.

Also, three levels of context are identified: computer, user and physical.

It is worth noting that the mobile application as a research tool proposed in this document complies with the dimensions of mobile computing and of contextaware M-Learning.

\section{2) Problem based Teaching}

In this article "Problem-Based Learning" (PBL) is used because some of the aims of the research is to address calculus problems and meet the guidelines of the Instituto Politécnico Nacional (IPN).

According to that described by García [12] the PBL complies with the following aspects.

It has particular impact on the student, being a working active methodology.

Allows the development of thinking skills, from the standpoint of critical and analytical, which are consolidated and endure over time and are open to other disciplines.

Looks for a comprehensive and plural development in students.

The protagonist of the Teaching-Learning Process (TLP) is the student.

Students work in discussion and reflection groups.

\section{Mathematics Education}

In Mathematics Education the fact that work in the classroom is contextualized has gained importance. This means that the concepts should be studied in a real situation instead of an abstract one by Solokowski [13].

On the other hand we also have Realistic Mathematics (REM Realistic Mathematics Education) which is based on the interpretation of the Mathematics of Freudenthal as "a human activity". From this perspective, students must learn 
Mathematics in order to mathematize an issue from a realistic situation and his own mathematization (i.e the context of the problems must be mathematically true for the student) by Freudenthal [14].

It's about learning Mathematics through rediscover the concepts involved within real problems, similar to how these were discovered for the first time in history. Reverse the process of teaching first formal and methodological aspects of mathematics and later its implementation. Seeking to address these issues in parallel, described in [15]-[17].

\section{Objective}

Evaluate, with a technological and educative methodology, the use of Mobile Computing in the TLP of Calculus using an innovative application that take advantage of the Mobile Computing potential.

\section{METHODOLOGY}

In order to accomplish the objective these methodological tools were used:
A. Diagnostic Questionnaire.
B. Application Design.
C. Activities Design.

\section{A. Diagnostic Questionnaire}

The diagnostic questionnaire consisted of nine questions and the tenth is on student opinion. This, was applied to 69 freshmen engineering and it was rated between $0-5$, zero was assigned to the problem that was solved incorrectly, while the five for the correct answer. If no data it means that the student did not answer the question. The questions focused on review both the conceptual and the algorithmic part of the students.

The questions are divided between the algorithmic and those requiring the concept, we observed that most of the students show deficiencies related to the concept.

The problems are numbered from one to nine, in several of them are asked questions marked with the letters a, b, c, d, e and $\mathrm{f}$.

The first problem, by having two subsections is divided into $1 \mathrm{a}$ and $1 \mathrm{~b}$.

The diagram shows a circle and a fixed point $\mathrm{P}$ on the circle. Lines PQ are draw from $\mathrm{P}$ to points $\mathrm{Q}$ on the circle and are extended in both directions. Such lines across a circle are called secants, and some examples are show in the diagram

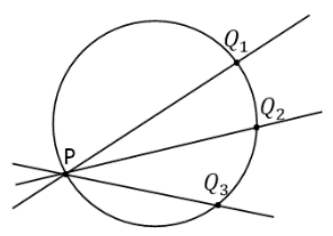

(a) How many different secants could be draw in addition to the ones already in the diagram?

(b) AS $Q$ gets closer and closer to $P$ what happens to the secant?

The second problem has not subsections, so in this case is just the number 2 .

Water is flowing into a tank at constant rate, such that for each unit increase in the time the depth of water increase by 2 units. The table and graph illustrate this situation.

\begin{tabular}{|l|c|c|c|c|c|c|}
\hline Time(x) & 0 & 1 & 2 & 3 & 4 & 5 \\
\hline Depth(y) & 0 & 2 & 4 & 6 & 8 & 10 \\
\hline Difference & & 2 & 2 & 2 & 2 & 2 \\
\hline
\end{tabular}

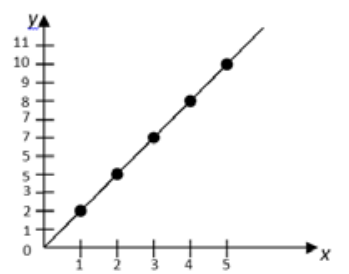

What is the rate of increase in the depth when $x=2 \frac{1}{2}$ ?

The third problem has five paragraphs, hence it is split into 3a, 3b, 3c, 3d, and 3e.

The graph below represents $y=3 x-1$.

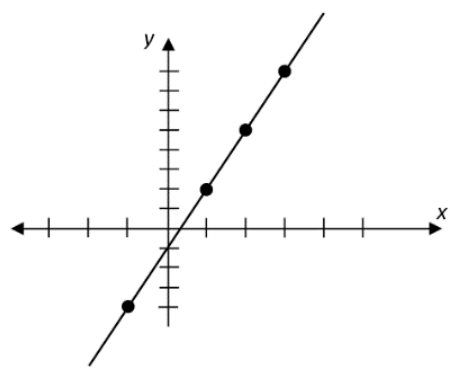

(a) What is the value of $y$ when $x=a$ ?

(b) What is the value of $y$ when $x=a+h$ ?

(c) What is the change in $\mathrm{y}$ as $\mathrm{x}$ increases from $a$ to $a+h$ ?

(d) What is the average rate of change in $y$ in the x-interval $a$ to $a+h$ ?

(e) Can you use the result (iv) to obtain the rate of change of $y$ at $x=2 \frac{1}{2}$ ? At $x=X$ ? If so, who?

The problem number six has three subsections therefore appears 6a, 6b, and 6c.

The graph of $y$ for certain equation, for $x=0$ to $x=6$, is shown below. 
What is the average rate of change of $y$ with respect to $x$,
(a) From $A$ to $B$ ?
(b) From $B$ to $E$ ?
(c) From $A$ to $J$ ?

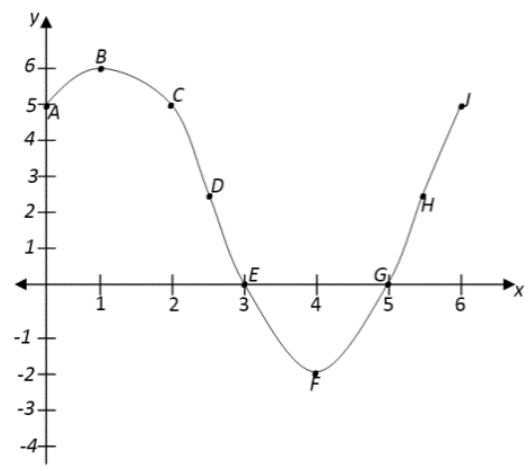

A total of 12 responses were reviewed, with each subsection. It is important to note that these 12 questions that were asked in the diagnostic questionnaire are algorithmic questions.

The following problems with their subsections are: $4,5 \mathrm{a}$, 5b, 5c, 7a, 7b, 7c, 7d, 7e, 7f, 8a, 8b, 8c, 9a, 9b, 9c. These problems are of algorithmic type or using the memory.

What is the formula for the rate of change for the equation $y=x^{n}$ ?

What is the rate of change formula for each of the following equations:
a) $y=\mathbf{3} x^{3}$ ?
b) $y=4$ ?
c) $y=\frac{2}{x^{2}}$

Explain the meaning of each of the following symbols:

(i) $\partial x$,

(ii) $\partial y(a)$,

(iii) $\frac{\partial y}{\partial x}$,

(iv) $d x$,

(v) $d y$,

(vi) $\frac{d y}{d x}$

What is the relationship between $\frac{\partial y}{\partial x}$ and $\frac{d y}{d x}$ ?

In each of the following, calculate the rate of change at the point indicated, and explain the significance of you answer:

$$
\begin{aligned}
& \text { (i) } y=x^{\mathrm{T}} 2-4(x+1 \quad \text { at } \\
& x=1 \text {, } \\
& \text { (ii) } y=x^{2}-4 x+1 \quad \text { at } \\
& x=2 \text {, } \\
& \text { (iii) } y=\frac{1}{x} \text { at } x=0
\end{aligned}
$$

\section{RESULtS}

In this section we present the results of the diagnostic questionnaire applied to the group of 69 freshmen engineering of first semester of Calculus.

The responses were organized into categories according to the strategy they used to solve the problems of the diagnostic questionnaire, these categories are described below.

Category called Substitute: This is one of the most common mistakes, the student substitute a value in an expression whether or not that was asked in an exercise.

Category called "Confuses concepts": When a student answers a question with a different concept, that may be correct but the learner is confusing two concepts.

Category called "Reduce its size": This error only occurs in Question 1 of the diagnostic questionnaire, since students state that the secant line reduces its size.

Category called "Same": This error only occurs in the question $7 \mathrm{~g}$. The student states the average change and the derivative are the same.

The results obtained are shown in the following graph in Figure 1.

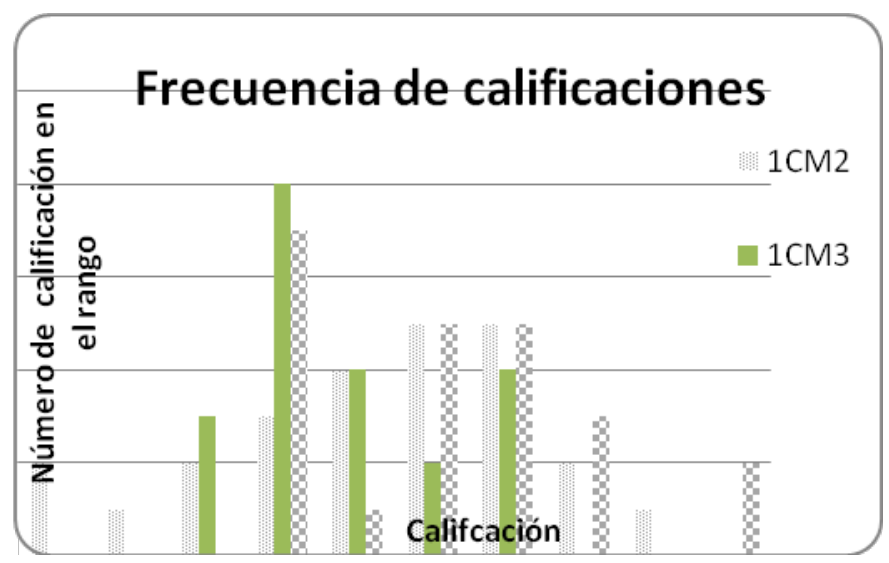

Fig. 1. Diagnostic Questionnaire Answer Graph. $y$ axe shows the number of answers with its grade in the range.

By taking the average of the ratings, only the ones responded well (rating between 1 and 5) we have the following. The algorithmic questions have an average rating of 
4.39 and the concept questions 3.96. This means that the students who answer correctly found easier the algorithmic questions.

The graph in Figure 2 shows the percentage response rate for each question (right or wrong). Where the average of the questions answered incorrectly is greater for the group of concept questions than the group of algorithmic questions. (46.98\% and $30.48 \%$, respectively)

This difference is increased with the analysis of the difficulties experienced by the students to respond. The error detected more frequently is that students substitute values in the expressions provided to them no matter what the exercise they were asked to respond. This happened both in Question 2 as in $3 e$.

The second most common mistake is to confuse the concepts they were asked.

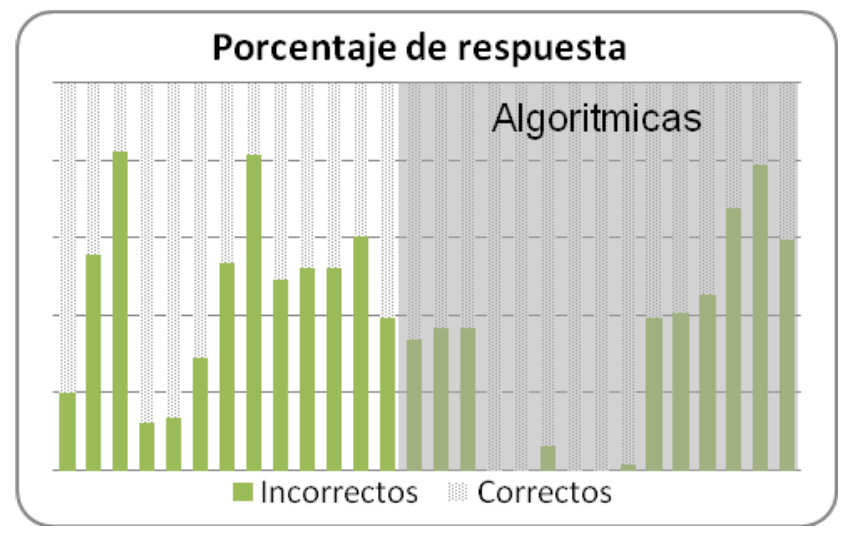

Fig.2. Show how algorithmic questions are correctly answered more frequently.

\section{APPLICATION DESIGN}

The application has the ability to acquire data under controlled conditions by the student and stores that data considering the time they were captured for granting independence in the form of use to the student and thus encourage innovation and independent learning, which allows a significant learning.

In the case of the camera, the most frequently feature found in mobile devices of students in Escuela Superior de Cómputo (ESCOM, IPN) in a previous study, it is possible to "paint" on it, similar to augmented reality, different base curves on the image to approximate the behavior of the object in the picture (Figure 3).
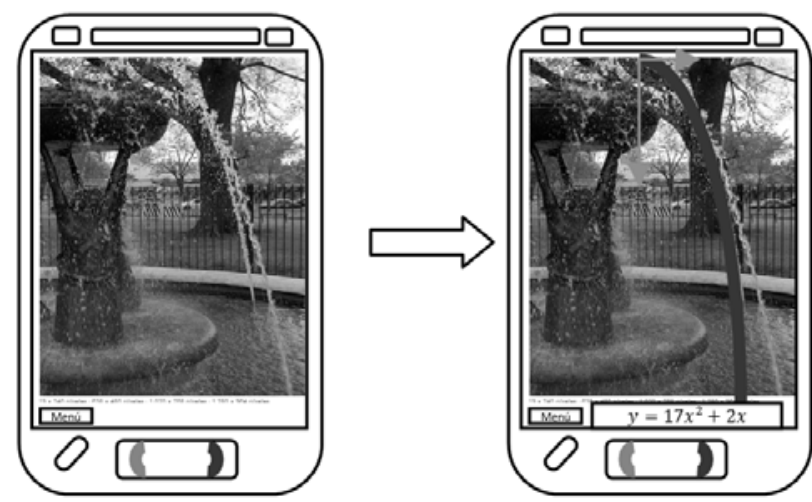

Fig. 3. Interface that allows "measure" over a taken picture.

The student should consider that the data provided by the application are in pixels and must convert these, if required, to a standard metric unit.

In addition to allowing the student to obtain the algebraic expression of the different curves drawn on the image, it is possible to perform measurements in the units specified, setting the conversion between pixels and units established.

The application allows the student to take measurements with the different features of the device, compass, microphone, accelerometer, etc.

For example, the level of the device can be used to measure angle changes according to time and draw the respective graph. See Figure 4.

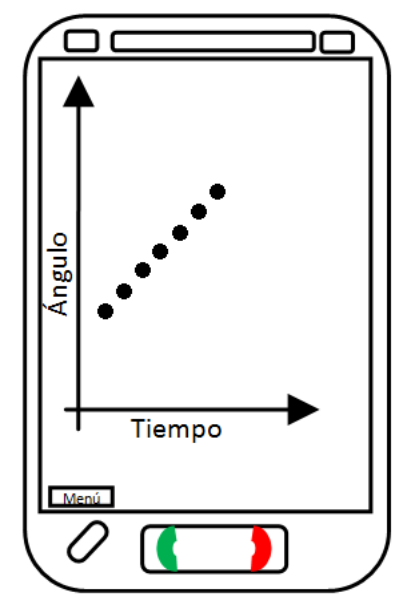

Fig. 4. The application allows the graphical view of the taken measurements

The application also stores the data on the device for later analysis, share data with peers and teachers using standard formats and communicating with Moodle.

After training students in the use of the application, which is intuitive, a problem to be solved in groups is proposed. These proposed problems are referred to as activities. Each activity has instructions for the student and the teacher, questions to be solved, these activities 
can be obtained from the web using a Moodle server or also to be printed on paper in order to have them on hand

ACTIVITY: WATER LEAK

\section{Motivation:}

After class two students stop by and watch a pipeline on the garden with a water leak, they say to each other:

- Look, a water leak

- Yeah, and they tell us to save

- Imagine that we could use that water as a weapon and could destroy a starship

They laugh and go report the water leak.

Problem

A water container having an orifice which generates leak is in the school. How full should be the container the water to reach dipping an object that is located a certain distance as shown in the figure. Find the rule correspondence between the height of the water level a the place that should be the object to be wet.

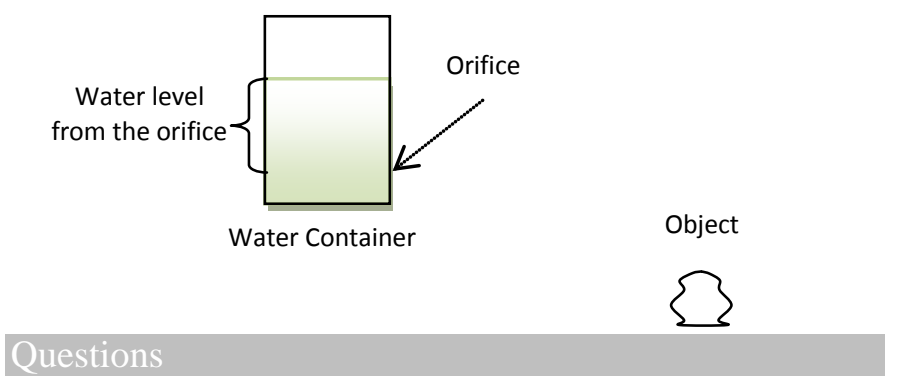

Before starting with the activity answer the following questions according to your own experience.

* If the relative position between the container and the object is given. What should be the water level from the orifice in order to wet the object?

* Which path will follow the trickle?

* How the container shape changes the path of the trickle?

* The path of the trickle is affected by the water volume contained?

What kind of container will you use?

Changing the container width modifies the distance of the object to be wet?

How does the orifice position affects the reach of the trickle? while capturing data.

An activity example is described in Figure 4.

Use your mobile device to discover the rule of correspondence between the water level and the place that should be the object to be wet.

1. Propose

2. Shoot a video.

a. Shoot a video of the described situation with your mobile device taking into account that the shoot let you perform measurements.

b. Once you shooted it determine the shape of the trickle and how it changes trought time.

c. Repeat the shooting with different containers in order to establish how its shape influences the path of the trickle.

d. Perform the necessary tests to answer the stated questions.

\section{Analysis}

Once you have experimented with the videos we propose you to label some distances involved in the problem in order to answer some qualitative questions.

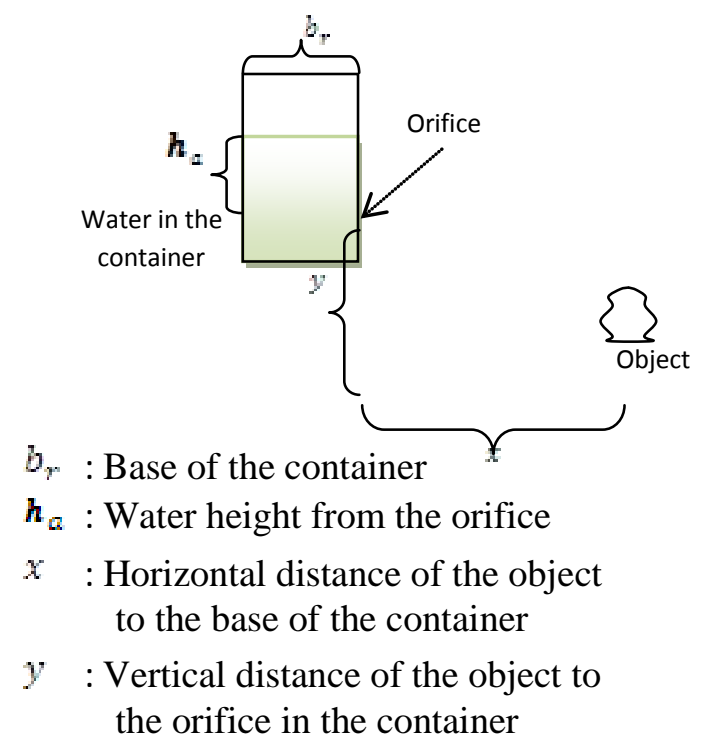

The distance $\boldsymbol{h}_{a}$ is a data that we can't control because it changes according to the water leak, it changes through time. Same happens with distance $x$. These are dependent variables. On the other hand $b_{\mathrm{w}}$ and $y$ are variables that we can fix.

\section{Analytic Expresions}

Suposing that the path of the trickle is a parable determine the constants $(a, b)$ of the following expression for a given moment 


$$
y=a x^{2}+b
$$

How can we rewrite this expression involving time?

What is the relation between constants $a$ and $b$ with $\boldsymbol{h}_{a}$ or $b_{\mathrm{x}}$ ?

Results

Write a final expression that could solve the original problem, i.e., if I have a container (height and width, if needed both or one of them) and an amount of water, in which position should be the object to be wet as soon as the container starts leaking.

Conclusions

To conclude argue with your classmates about how this problema reflects the concept of function: domain, image or range, correspondence rule, dependent and independent variables and functions composition.

Fig.5 Activities format. Activity sample

\section{ANALYSIS}

The observations made to students while they were solving activity shown in Figure 4.

Now we present the conclusions reached by the group of students about the activity applied. To solve it the group was divided into 7 teams.

Team 6 concluded that the amount of water is an important factor influencing the pressure on the orifice and this is reflected in the distance of the water.

Team 6 also noted that they weren't able to express the function algebraically they just got conclusions regarding the practice and knowledge obtained. But this allowed them to understand what was really happening instead of the sole algebraic expression that did not tell them anything. This team commented that using different applications within their phone to solve a math problem is something totally new. Exemplified the fact that they are used to take video or take photos to things outside of what they work at school, noting that most of them have used the camera to take a picture to the board, instead of taking notes.

Team 2 indicated that the function is decreasing as the pressure at which water leaks depends on the height of the orifice and the shape of the container.

For this team to use their phones was something different and interesting because they solve a math problem using applications included in their mobile devices and the application installed by the teacher helped them a lot, they could draw a graph and measure the distance between the object and the vessel containing the liquid. This makes mathematics realistic, not abstract.

Team 5 said that the scope of the trickle to the object depends on the pressure with which it leaves the container and what is obtained is a decreasing function as this is due to the height of the liquid that wets the object and the loss of pressure as the liquid is ejected.

Team 7: concluded that the function being sought depends upon the amount of water and the container that serves as an experiment, it was also noted that it is decreasing because water within it, is depleted.

\section{CONCLUSION}

In this first phase of the research that has been developed and shown in this article, we note the importance of the use of Mobile Computing in Education, specifically in Mathematics Education, currently young students have access to Mobile culture, so that the application designed and the activities formulated were directed to use what the student knows. On the other hand the design of the application and the proposed activities were aimed to work the deficiencies found in undergraduate Computer Science students of first semester, as a result of applied a diagnostic questionnaire, where when contrasted with the literature found great similarity, and students prefer to solve algorithmic issues to situations where the concept of function is involved more realistically.

The impact of working with mobile devices allowed the student to solve the activity using the application installed on their phones in different moments of resolution, such as drawing the coordinate plane and graph a parabole corresponding to the water leak, but this was achieved by the students because they shot a video when the water container was emptied through the orifice made in it.

The usability of their phones was a fundamental key, just like the portability of these.

The impact of mobile computing that was evaluated was the Usability part of M-Learning and found the following: Having worked with the activities and the designed application we performed an evaluation questionnaire and one on the usability and found that the students were able to develop different skills such as reflection, communication and discovery.

In relation to learning obtained, it was more significant, it was not mechanical.

It is considered that the contribution of Mobile Computing consisted of a comprehensive development of the student in order to achieve learning that is not based on memory.

\section{REFERENCES}

[1] Johnson, L.; Levine, A.; Smith, R., (2010). The 2010 Horizont Report. Austin, Tejas: The New Media Consortium.

[2] Johnson, L.; Smiths, R.; Williams, H., (2011). The 2011 Horizont Report. Austin, Tejas: The New Media Consortium.

[3] Johnson, L.; Adams, S.; Cummins, M. (2012). Informe Horizon del NMC: Edición para la enseñanza 
universitaria 2012. Austin, Tejas: The New Media Consortium.

[4] Kurkovsky, S. (2012). Integrating mobile culture into computing education. Integrated STEM Education Conference (ISEC), IEEE 2nd , 1(4), 9-15 March 2012

[5] Ausubel, D., Novak, J., Hanesian, H., (1983) Psicología Educativa: Un punto de vista cognoscitivo. $2^{\mathrm{a}}$. Edición Trillas. México.

[6] Aravena, M. (2002). "Evaluación de procesos de modelización polinómica mediante proyecto”, Didáctica de las matemáticas 31,. 44-56.

[7] Aravena, M. (2008). Modelos Matemáticos a través de proyectos. Revista Latinoamericana de Investigación en Matemática Educativa. 11(1), 49-92.

[8] Biembengut, M. y Hein, N. (2004) Modelación matemática y los desafíos para enseñar matemática. Educación Matemática. 16 (2),105-125.

[9] M. Artigue, R. Douady, L. Moreno. (1995) Ingeniería didáctica en Educación matemática. Grupo Editorial Iberoamérica. Bogotá.

[10] B'Far, R. (2005) Mobile Computing Principles designing and developing mobile applications with uml and xm.. Cambridge University Press. USA.

[11] Chuantao Yin; David, B.; Chalon, R., (2009). Use your mobile computing devices to learn - Contextual mobile learning system design and case studies. Computer Science and Information Technology, 2009. ICCSIT 2009. 2nd IEEE International Conference 1(1), 8-11

[12] García, L. Moreno, M. Azcárate C. (2006). EBP como metodología activa para la enseñanza del cálculo diferencial. XIV Jornadas de ASEPUMA y II Encuentro Internacional.

[13] Sokolowski, A., Yalvac, B. \& Loving, C. (2011). Science modeling in pre-calculus: how to make mathematics problems contextually meaningful. International Journal of Mathematical Education in Science and Technology. 42(3), 283-297.

[14] Freudenthal, H., (1991) Revisiting Mathematics Education. Dordrecht: Kluwer Academic.

[15] Julie-Ann Edwards (2013). Collaborative Group for Research in Mathematics Education. Consultado en 2013.

http://www.southampton.ac.uk/education/about/staff/jse 1.page

[16] Mette, A. (2007). Understandings of Modelling. Working group 13. Congress of the European Society for Research in Mathematics Education 5. pp 2042

[17] Rasmussen, C., King, K. (2000). Locating starting points in differential equations: a realistic mathematics education approach. International Journal of
Mathematical Education in Science and Technology, 31(2), $161-172$.

\section{Creative Commons Attribution License 4.0 (Attribution 4.0 International, CC BY 4.0)}

This article is published under the terms of the Creative Commons Attribution License 4.0 https://creativecommons.org/licenses/by/4.0/deed.en US 